\title{
Evidence-based approach to HIV/AIDS policy and research prioritization in the Islamic Republic of Iran
}

\author{
A. Feizzadeh, ${ }^{1,2}$ S. Nedjat, ${ }^{2,3}$ S. Asghari, ${ }^{2}$ A. Keshtkar, ${ }^{4}$ R. Heshmat, ${ }^{2}$ H. Setayesh ${ }^{7}$ and R. Majdzadeh ${ }^{2,3}$
}

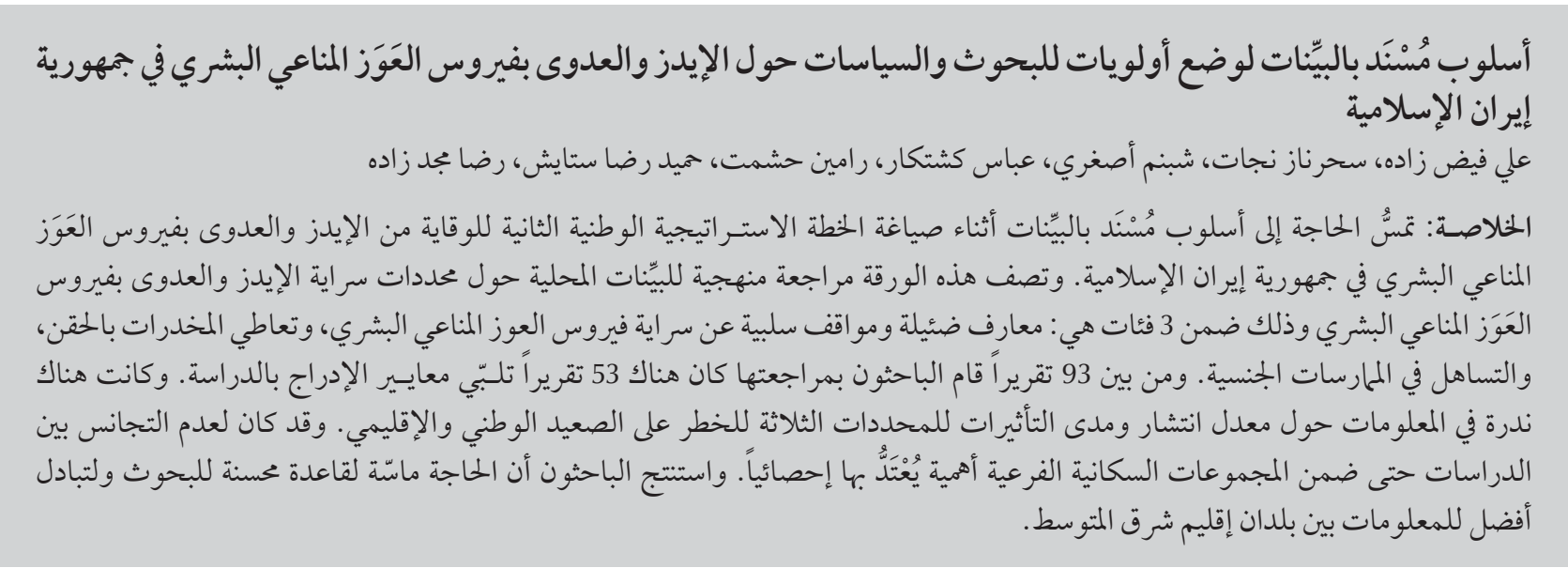

ABSTRACT In formulating the second national strategic plan for prevention of HIV/AIDS in the Islamic Republic of Iran a more evidence-based approach was needed. This paper reports on a systematic review of the local evidence about the determinants of HIV/AIDS transmission in 3 categories: poor knowledge and negative attitudes about HIV transmission; injection drug use; and sexual promiscuity. Of 93 reports reviewed, 53 met the inclusion criteria. Information about the prevalence and magnitude of effect for the 3 risk determinants at the national and regional level was scarce. Heterogeneity between studies, even in the same sub-population, was significant. An improved research base and better sharing of information are needed within countries of the Eastern Mediterranean Region.

Approche fondée sur des bases factuelles de la politique relative au VIH/sida et établissement des priorités de la recherche en République islamique d'Iran

RÉSUMÉ Lors de l'élaboration du second plan national stratégique pour la prévention du VIH/sida en République islamique d'Iran, une approche davantage fondée sur des données factuelles s'est avérée nécessaire. Cet article présente une étude systématique des données locales sur les déterminants de la transmission du VIH/sida dans trois domaines : méconnaissance et attitudes négatives vis-à-vis de la transmission du VIH, consommation de drogues par voie intraveineuse et promiscuité sexuelle. Sur 93 rapports étudiés, 53 d'entre eux satisfont les critères d'inclusion. Les informations relatives à la prévalence et à l'amplitude de l'effet des trois déterminants du risque aux niveaux national et régional étaient peu nombreuses. L'hétérogénéité des études, y compris dans la même sous-population, était importante. Une meilleure base de recherche et un meilleur partage des informations sont nécessaires dans les pays de la Région de la Méditerranée orientale. 


\section{Introduction}

The Joint United Nations Programme on HIV/AIDS (UNAIDS) estimates the number of people living with HIV in the Islamic Republic of Iran at 66000. Thus, while HIV prevalence among women aged $15-49$ years is well below the $1 \%$ threshold which defines a generalized epidemic, prevalence estimates of more than 5\% among injection drug users (IDUs) mean that the country is facing a concentrated HIV epidemic [1].

The Iranian National AIDS Committee harmonizes the national response to HIV/AIDS through a strategic framework. The first national strategic plan (years 2002-06) was mainly based on consensus among policy-makers and academics and was not fully evidence-based. The plan was based on 11 main strategies, including education and information, IDU, harm reduction and prevention of motherto-child transmission, the latter related more to case-finding and treatment. A good strategic plan for prevention of HIV/AIDS should cover all at-risk and high-risk populations and allocate resources based on current and projected priorities. These broadly-defined populations should be translated into specific groups in each society based on the local context. It was therefore decided during the mid-term review of the first strategic plan that a more evidence-based approach was needed in formulating the second strategic plan (years 2007-10). For any risk factor for a disease, knowing its factual prevalence, its counterfactual prevalence and the magnitude of its effect can help estimate the avoidable burden of that disease [2].

The current research was a systematic review of the evidence under 3 main search themes. At the time of this study in 2005 the debate about HIV in the Islamic Republic of Iran hinged on whether the epidemic was shifting from predominately IDU-based transmission to heterosexual transmission. We therefore chose to investigate the following risk factors for HIV transmission: poor knowledge and negative attitudes about transmission of HIV; IDU; and sexual promiscuity. At the time, there was no published review from the Islamic Republic of Iran about the prevalence and magnitude of effect of any of these factors. The available evidence would then be used to determine policy priorities for the second national strategic plan, while the gap between the evidence needed and that available would help to determine research priorities.

\section{Methods}

We used a systematic review approach to find the prevalence and magnitude of effect of each of the 3 risk determinants.

\section{Systematic review}

All domestic and foreign electronic and nonelectronic databases which were accessible and websites of key centres and institutes were searched. We consulted conference abstracts, theses, journals (Iranian and foreign), the references of articles and the "grey literature". Experts were questioned about the relevant literature too.

The following databases were searched: IranMedex (http://www. iranmedex.com, a private company databank of articles published in Iranian biomedical journals); Irandoc (http:// www.irandoc.ac.ir, a database of postgraduate theses and dissertations); Scientific Information Database (http:// www.sid.ir; a database of articles published in Iranian scientific research journals); Cochrane Library; Medline; and Embase. The following Iranian public institutions were consulted: Ministry of Health and Medical Education, State Welfare Organization, Ministry of Culture and Islamic Guidance, Centre for Disease Control and Prisons Organization. We also consulted
Iranian nongovernmental organizations (NGOs), research centres and the media as well as international NGOs and UN agencies, including the World Health Organization.

The keywords used for electronic and manual searches were as follows: knowledge and attitude (health education, health knowledge, attitudes, practice, perception) towards high-risk behaviours including sexual behaviour (unsafe sex, homosexuality and heterosexuality, risk behaviour, prostitution, needle sharing, intravenous substance and drug abuse, sexually transmitted infections), in combination with the keywords HIV and AIDS.

The inclusion criteria for information were: no earlier than 1994; a defined population (in prevalence studies) and a well-defined exposure and outcome (in analytic studies).

For each risk factor measure we used a data extraction form with items including: study population, date and location of study, estimated measure and study quality indicators. The quality of the reports was assessed by considering the study population and design, examining biases and confounding factors.

Data from the forms were entered into 3 different evidence tables for the 3 search themes.

\section{Data analysis}

Based on the possibility ofdifferentsubpopulations, we conducted sub-group analysis to reduce the heterogeneity within each sub-group. After excluding the remaining qualitative heterogeneity, quantitative heterogeneity graphical and statistical methods, i.e. forest and radial plots and chi-squared [3] statistical tests were utilized. All analyses were performed using Stata SE, version 8.0.

\section{Results}

The findings are reported and tabulated under the 3 search themes. 


\section{Poor knowledge and negative attitudes about HIV transmission}

There were 35 reports about poor knowledge and negative attitudes to HIV; 26 of them met the inclusion criteria and were entered in the study (Table 1). The reports were divided into 6 groups based on the study population (health care workers, school and college students, runaway girls and female commercial sex workers, barbers and hairdressers, and general population); the summary measure was calculated separately for each group.

Although we aimed to estimate the summary for each subgroup, the variety of responses did not allow this. For example poor knowledge varied from $1.6 \%$ to $90 \%$ of the population. Hence, in all cases except one (in which chisquared $=0.08$ ) the chi-squared value for heterogeneity was significant in all cases. We also intended to use funnel plots for subgroups with a sufficient number of studies, but the large heterogeneity within each subgroup (due to differences in study quality, a possible time trend and inconsistent definitions of poor knowledge and attitude) made it impossible to differentiate between heterogeneity and possible publication bias, in fact any source of information bias. As there was no information regarding the magnitude of effect for this risk determinant on HIV transmission, it was impossible to estimate the avoidable burden of risk related to poor knowledge and negative attitudes.

\section{Injection drug use}

We identified 48 reports in the category of IDU, of which 18 met the inclusion criteria. The reports were divided into 2 groups: IDU in prison and other correctional facilities and IDU in the community, including drop-in centres and outpatient treatment facilities (Table 2). Many of the reports in this category could be classified as "grey literature", obtained from key resource people in the public sector and were mainly based on unpublished registry data.

As there was significant qualitative heterogeneity among reports, even within each stratum, we did not use meta-analysis methods. There was no report on effect size for IDU as a risk for HIV infection. However, analysis of the crude results of one study yielded an odds ratio of 3 for having HIV infection among IDUs compared with noninjection drug users [4].

\section{Sexual promiscuity}

Because of the cultural taboos surrounding extramarital sex in any form in the Islamic Republic of Iran, reports on sexual promiscuity and commercial sex work were scarce and mostly methodologically unacceptable. However, we included all the reports we identified as they provided the only available information (Table 3). It should be noted that the definitions of commercial sex work, promiscuous sexual behaviour and breach of Islamic law by women overlapped loosely in the reports. There was no report on men who have sex with men.

Due to the profound heterogeneity of the reports, we decided not to conduct any meta-analysis or use scenario-based estimations. There were 2 unofficial reports providing estimates of the number of commercial sex workers in the Islamic Republic of Iran, one estimating it as 60000 and another as 50000.

\section{Discussion}

A key finding of this study was the scarcity of information, at both the national and regional level, regarding the magnitude of effect for the 3 risk determinants studied. While it would be possible to utilize measures from studies in other countries, such estimates might not be applicable for policy-making in the Islamic Republic of Iran because of fundamental social, cultural and economic differences, as well as epidemiological differences [5]. Another finding was the considerable heterogeneity between studies, evenin the samesub-population, which made it impossible to estimate the prevalence of risk determinants. The shortage of information needed to estimate the magnitudes of effects and prevalence made it impossible to make even an educated guess about the avoidable burden of any of the 3 risk determinants. The heterogeneity was statistically significant, as evident from significant chi-squared tests. Therefore, there appears to be a qualitative source for the heterogeneity, which cannot be explained by simple random variation in findings that could be treated by random-effects meta-analysis techniques.

The observed heterogeneity may also be attributed to other factors: the relatively long period covered by the study and possible time-related changes in the risk profile of the country; the considerable differences in the quality of studies; and inconsistency in the operational definition of risk determinants in different studies. There was also evidence of delays in the publication of many reports and papers. The results cannot therefore be compared even in similar target populations.

One of the limitations of this study was that we were not certain of having found all the existing evidence. Many of the reports cited in this study were initially produced only for internal circulation within an organization. In addition, evidence on sexual relations between men, which could be important, was non-existent. This can be explained by the very strong cultural taboos surrounding homosexuality in Muslim countries and the corresponding dearth of opportunities to investigate the issue.

The systematic review method helps identify information and evidence gaps that should be filled if planning and policy-making are to be truly evidencebased. In many developing countries, including ours, the infrastructure for generating and sharing evidence is 


\begin{tabular}{|c|c|c|c|c|c|c|c|}
\hline \multirow{2}{*}{$\begin{array}{l}\text { Study group/location } \\
\text { [reference] }\end{array}$} & \multirow{2}{*}{$\begin{array}{l}\text { Year of } \\
\text { study }\end{array}$} & \multirow{2}{*}{$\begin{array}{l}\text { Sample } \\
\text { size }\end{array}$} & \multirow{2}{*}{$\begin{array}{c}\begin{array}{c}\text { Poor } \\
\text { knowledge }\end{array} \\
\%\end{array}$} & \multirow{2}{*}{$\begin{array}{c}\text { Negative } \\
\text { attitudes } \\
\% \\
\%\end{array}$} & \multicolumn{3}{|c|}{ Statistics } \\
\hline & & & & & $\begin{array}{c}x^{2} \text { for } \\
\text { heterogeneity }\end{array}$ & $P$-value & $\begin{array}{c}I^{2} \text {-value } \\
\%\end{array}$ \\
\hline \multicolumn{8}{|l|}{ Health care workers } \\
\hline Kerman [6] & 1994 & 105 & 34.3 & - & 160.2 & $<0.001$ & 98 \\
\hline Shiraz [7] & 1997 & 47 & 74.4 & - & & & \\
\hline Yazd [8] & 1997 & 168 & 4.2 & - & & & \\
\hline Karaj [9] & 2002 & 217 & 3.7 & 0.5 & & & \\
\hline \multicolumn{8}{|l|}{$\begin{array}{l}\text { High-school and college } \\
\text { students }\end{array}$} \\
\hline Hamadan [10] & 1996 & 1272 & 32.2 & - & 4501 & $<0.001$ & 66 \\
\hline Yazd [17] & 1999 & 1850 & 58.2 & 14.4 & & & \\
\hline Tehran [12] & 2000 & 646 & 46.1 & - & & & \\
\hline Babol [13] & 2000 & 81 & 20.3 & 48.1 & & & \\
\hline Babol [13] & 2000 & 69 & 48.1 & 56.5 & & & \\
\hline Astara $^{a}$ & 2002 & 163 & 11.3 & - & & & \\
\hline Tehran [14] & 2002 & 4641 & 22.3 & - & & & \\
\hline Tehran $^{b}$ & 2004 & 424 & 0.0 & 31.0 & & & \\
\hline Shiraz $^{c}$ & 2004 & 288 & 9.4 & - & & & \\
\hline \multicolumn{8}{|l|}{ Prisoners } \\
\hline Zanjan [15] & 1998 & 284 & 54.7 & - & 10457 & $<0.001$ & 94 \\
\hline Dezful $^{d}$ & 2002 & 205 & 15.1 & - & & & \\
\hline Countrywide $^{e}$ & 2003 & 2251 & 28.5 & 21.5 & & & \\
\hline \multicolumn{8}{|c|}{$\begin{array}{l}\text { Runaway girls and female } \\
\text { commercial sex workers }\end{array}$} \\
\hline Kermanshah $^{a}$ & 2002 & 50 & 33.3 & - & 5.05 & 0.08 & 94 \\
\hline Tehran [16] & 2003 & 110 & 38.9 & 59.3 & & & \\
\hline Shiraz [17] & 2004 & 106 & 25.0 & - & & & \\
\hline \multicolumn{8}{|l|}{ Barbers and hairdressers } \\
\hline Gorgan [18] & 2000 & 150 & 56.2 & 43.4 & 144 & $<0.001$ & 92 \\
\hline Boroujerd [19] & 2003 & 200 & 13.0 & - & & & \\
\hline Sari $[20]$ & 2003 & 199 & 5.5 & - & & & \\
\hline \multicolumn{8}{|l|}{ General population } \\
\hline West Azerbaijanf & 1996 & 504 & 44.0 & - & 12000 & $<0.001$ & 73 \\
\hline Sanandaj [27] & 1998 & 852 & 33.7 & - & & & \\
\hline Kermanshah [22] & 2000 & 2300 & 90.0 & - & & & \\
\hline Tehran [23] & 2001 & 400 & 1.6 & 22.3 & & & \\
\hline Astara $^{a}$ & 2002 & 100 & 24.2 & - & & & \\
\hline Saravan $^{a}$ & 2002 & 100 & 32.9 & - & & & \\
\hline Eslamshahr ${ }^{a}$ & 2002 & 140 & 12.7 & - & & & \\
\hline Tehran [24] & 2003 & 1172 & 13.7 & - & & & \\
\hline Shiraz [25] & 2004 & 1200 & 11.2 & - & & & \\
\hline
\end{tabular}

aMalakafzali H. A multidisciplinary prevention/management program for HIV/AIDS in high risk areas of Iran, unpublished report, 2002.

${ }^{b}$ Aria P et al. Knowledge, attitude, and practice of youngsters about AIDS in 17th municipality district of Tehran, unpublished report 2004.

'Mirahmadizadeh A, Hemati A. Effect of health education on knowledge, attitude, and practice in Shiraz population, unpublished report, 2004.

${ }^{d}$ Kazemi M et al. Knowledge of Dezful Fajr addict prisoners toward AIDS, unpublished report, 2002.

${ }^{e}$ Moradi Lakeh M, Afshar P. Knowledge, attitude, and practical skills of prisoners about health priorities in prisons, unpublished report, 2003.

fShariatzadeh M et al. Knowledge attitude and skills towards AIDS in West Azerbaijan, unpublished report, 1996. 


\begin{tabular}{|c|c|c|c|c|c|}
\hline \multirow[t]{3}{*}{ Study group/location [reference] } & \multirow{3}{*}{$\begin{array}{c}\text { Year of } \\
\text { study }\end{array}$} & \multirow{3}{*}{$\begin{array}{c}\text { Sample } \\
\text { size } \\
\text { No. }\end{array}$} & \multirow{3}{*}{$\begin{array}{l}\text { IDU } \\
\%\end{array}$} & \multicolumn{2}{|c|}{ HIV-positive } \\
\hline & & & & \multirow{2}{*}{$\begin{array}{c}\text { Non-IDU } \\
\%\end{array}$} & \multirow{2}{*}{$\begin{array}{c}\text { IDU } \\
\%\end{array}$} \\
\hline & & & & & \\
\hline \multicolumn{6}{|l|}{ Inside prison } \\
\hline Shiraz, rehabilitation camp ${ }^{a}$ & 1999 & 1061 & 44.0 & 0.76 & 1.2 \\
\hline Countrywide, rehabilitation camps ${ }^{b}$ & 2000 & - & - & 1.14 & - \\
\hline Countrywide, drug-related prisoners [26] & 2000 & - & - & 3.3 & - \\
\hline Countrywide, prisons [26] & 2002 & 2799 & 23.1 & - & 4.0 \\
\hline Tehran, prison ${ }^{c}$ & 2003 & 370 & 50.0 & - & 24.0 \\
\hline Countrywide, prisons ${ }^{d}$ & 2003 & 2251 & 9.8 & - & - \\
\hline Countrywide, prisons [27] & 2003 & 2437 & - & - & 4.0 \\
\hline \multicolumn{6}{|l|}{ Outside prison } \\
\hline Countrywide [28] & 1998 & 1500 & 21.2 & - & - \\
\hline Tehran [29] & 2000 & - & $>5.0$ & - & - \\
\hline Tehran [30] & 2001 & 65 & 35.7 & - & - \\
\hline Tehran [4] & 2002 & 200 & 14.0 & 5.0 & 15.0 \\
\hline Countrywide [37] ${ }^{e}$ & 2002 & - & 24.0 & - & - \\
\hline Kermanshahf & 2001 & 384 & - & - & 16.1 \\
\hline Countrywide $[32]^{e}$ & 2003 & - & $\begin{array}{l}4000-9000 \\
\text { females (No.) }\end{array}$ & - & - \\
\hline Countrywide ${ }^{g}$ & 2003 & - & 242000 (No.) & & \\
\hline Kermanshah, triangular clinic ${ }^{h, i}$ & 2002 & 697 & 31.0 & \multicolumn{2}{|c|}{25.0 (among all drug users) } \\
\hline
\end{tabular}

aPrisons Organization, unpublished report.

${ }^{b}$ Bolhari J. Drug abuse in prisons in Iran, unpublished report, 2002.

'Farhoudi B, Afshar P. HIV-TB co-infection and risk factors in injection drug users in a prison in Iran, unpublished report, 2003.

${ }^{`}$ Moradi Lakeh M, Afshar P. Knowledge, attitude, and practical skills of prisoners about health priorities in prisons, unpublished report, 2003.

${ }^{e}$ This reference is a review not primary research.

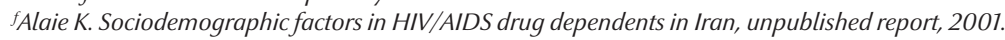

${ }^{g}$ Vazirian M. A review of demand reduction programs in Iran: recommendations for strategic development plans, unpublished report, 2003.

${ }^{h}$ Kermanshah provincial health centre, personal communication.

'Triangular clinics are facilities providing services dealing with injection drug use, sexually transmitted infections and HIV.

poorly developed and the studies that are conducted do not follow standard research guidelines or protocols. In line with global recommendations for utilizing knowledge in health decisions
[33,34], the Islamic Republic of Iran has also taken steps toward reducing the gap between knowledge and practice by development of educational capacity-building programmes in the field of systematic reviews, practice guidelines and knowledge translation [35].

However, the great heterogeneity of the studies identified in our systematic search means that they could not

\begin{tabular}{|c|c|c|c|}
\hline Location & Study group & Year of study & HIV-positive (\%) \\
\hline Kermanshah ${ }^{\mathrm{a}}$ & Women in prison for misdemeanours against Islamic laws & 2001-03 & 2.4 \\
\hline Kermanshah ${ }^{b}$ & HIV test volunteers who had unsafe sex & 2001-02 & 13.0 \\
\hline Kemranshac $^{c}$ & CSW & - & 3.0 \\
\hline Kohkilouye ${ }^{c}$ & Homeless CSW & - & 11.0 \\
\hline Charmahal $^{\mathrm{c}}$ & Homeless CSW & 2000 & 14.0 \\
\hline Countrywide $^{b}$ & STI clinic patients (male and female) & - & 0.02 \\
\hline Unnamed district ${ }^{\mathrm{b}}$ & HIV test volunteers with no IDU history & - & 9.0 \\
\hline
\end{tabular}

${ }^{a}$ Kermanshah provincial health centre, personal communication.

${ }^{b}$ Ministry of Health, personal communication.

cPrisons Organization, personal communication.

$C S W=$ commercial sex workers; $S T I=$ sexually transmitted infections; IDU = injection drug use. 
be used as evidence to guide policy and planning. Accordingly, we recommend that the relevant government bodies take steps to establish the necessary infrastructure for improving the research base in HIV/AIDS.

We also recommend the development of a virtual network of all the producers and users of HIV/AIDS-related information at country level as well as a strengthening of existing regional links to facilitate the sharing of knowledge between countries of the Eastern Mediterranean Region in order to plug the gaps in the evidence. Monitoring and evaluation of current interventions on HIV/AIDS prevention deserve more attention.

Finally, information about risk behaviours for HIV transmission as well as
HIV incidence and prevalence trends in different populations within the Islamic Republic of Iran needs to be analysed alongside routine reporting data within a comprehensive, unified system under the leadership and support of the $\mathrm{Na}$ tional AIDS Committee.

\section{Acknowledgements}

The authors wish to acknowledge with thanks all the individuals who provided them with their reports, especially Dr Behnam Farhoudi, Dr Sepideh Sigari, and Dr Parviz Afshar from the Prisons Organization, Dr Hengameh Namdari from Kermanashah health centre, Dr Kianoosh Kamali from the National
AIDS Programme (Ministry of Health and Medical Education), and Dr Alireza Mirahmadizadeh. We would also like to thank Dr Kamran Yazdani for reviewing the manuscript draft and Dr Alireza Vassigh for reviewing the final manuscript.

The study was done with full financial support from the United Nations HIV/AIDS Theme Group (UNAIDS). Hamidreza Setayesh is now the UNAIDS Country Officer but at the time of grant confirmation and most parts of the study he was UNICEF Health Officer. None of the other authors has any conflict of interest either with the granting agency or the information sources used for the review.

\section{References}

1. 2006 Report on the global AIDS epidemic. Geneva, Joint United Nations Programme on HIV/AIDS, 2004.

2. Greenland S. Causality theory for policy uses of epidemiological research. In: Murray CJL et al. eds. Summary measures of population health: concepts, ethics, measurement and applications. Geneva, World Health Organization, 2002:291-301.

3. Higgins JPT et al. Measuring inconsistency in meta-analyses. British medical journal, 2003, 327:557-60.

4. Zamani $\mathrm{S}$ et al. Prevalence of and factors associated with HIV-1 infection among drug users visiting treatment centers in Tehran, Iran. AIDS, 2005, 19:709-16.

5. Rothman KJ, Greenland S, Timothy L. Modern epidemiology, 3rd ed. Philadelphia, Lippincott-Raven, 2008.

6. Aminipour E, Ameri G. [Knowledge of school nurses about AIDS.] Journal of Sabzevar University of Medical Sciences, 1997, 1:53-8 [in Farsi].

7. Shojaiezadeh D. [Evaluation of AIDS health education program on knowledge, attitude, and practice of experimental assistant dentists in Shiraz.] Journal of Tehran Faculty of Medicine, 1997, 6:116-20 [in Farsi].

8. Zarifnasab M et al. [Influence of education on knowledge of working nurses concerning AIDS.] Journal of Shahid Sadoughi University of Medical Sciences and Health Services, 1999, 2:57-62 [in Farsi].

9. Sotoudeh M, Eftekhar H, Gouya M. Knowledge, attitude, and practice in health workers of a health center in Karaj about universal precaution [MPH thesis]. Tehran, Islamic Republic of Iran, Tehran University of Medical Sciences, School of Public Health, 2002.

10. Fathi Y, Tavakol M. [Students' knowledge in Hamadan University of Medical Sciences about AIDS in 1995-96.] Scientific Journal of Hamadan University of Medical Sciences Health Services, 1996, 7:40-6 [in Farsi].

11. Karimi $\mathrm{M}$ et al. [Attitude and knowledge of high school students in Yazd towards AIDS.] Journal of Shahid Sadoughi University of Medical Sciences Health Services, 2000, 4:5-10 [in Farsi].
12. Gachkar L, Amini M. [A study into knowledge and perception of female high-school students on AIDS, Tehran, 2000.] Pajouhandeh quarterly research journal, 2001, 23:287-91 [in Farsi].

13. Omidvar SH. [Knowledge level and attitude of midwifery and nursing students regarding AIDS, Babol, 2000.] Journal of Babol University of Medical Sciences, 2003, 2:37-41 [in Farsi].

14. Tavoosi A et al. Knowledge and attitude towards HIV/AIDS among Iranian students. BMC public health, 2004, 4:17-23.

15. Vakili MM. [A study of the addicted men's knowledge and attitude measurement in Zanjan central prison about AIDS.] Journal of Zanjan University of Medical Sciences and Health Services, 1998, 23:17-23 [in Farsi].

16. Ardalan A et al. [Survival sex, an outcome of running away for girls.] Social welfare quarterly, 2002, 2:187-219 [in Farsi].

17. Honravar B, Negin $\mathrm{H}$. [Knowledge, attitude, and practice of female engaged in temporary marriage in Shiraz toward AIDS, 2003-4.] In: Proceedings of the Second National Congress on Epidemiology, Zahedan, Islamic Republic of Iran, 2004 [in Farsi].

18. Mahmoudi G, Hosseini SA. [Knowledge, attitude and performance of barbers about AIDS prevention.] Journal of Gorgan University of Medical Sciences, 2000, 5:32-6 [in Farsi].

19. Amini M, Shojaizadeh D. Knowledge and attitude of hairdressers towards AIDS in Broujerd [thesis]. Tehran, Islamic Republic of Iran, Tehran University of Medical Sciences, School of Public Health, 2003.

20. Naghibi SA, Asadpour A. [Knowledge of barbers towards HBV and AIDS in Sari 2003.] In: Proceedings of the Second National Congress on Epidemiology, Zahedan, Islamic Republic of Iran, 2004 [in Farsi].

21. Memar N. [Knowledge of people over 15 years old about prophylaxis and transferring of AIDS and Hepatitis B in Sanandaj.] Journal of the Medical Faculty of Guilan University of Medical Sciences, 2001, 37:13-8 [in Farsi].

22. Darabi F. Study of the knowledge of people about AIDS in Kermanshah, 2001. Behboud, Journal of Kermanshah University of Medical Sciences, 2000, 3:64-70. 
23. Asghari S, Majlesi F. Knowledge and attitude of marriage candidates towards HIV/AIDS in a health center in Tehran [MPH thesis] Tehran, Islamic Republic of Iran, Tehran University of Medical Sciences, School of Public Health, 2001.

24. Montazeri A. AIDS knowledge and attitudes in Iran: results from a population-based survey in Tehran. Patient education and counselling, 2005, 57:199-203.

25. Mirahmadizadeh AR et al. [Prevalence of HIV infection among intravenous drug addicts in Shiraz, 1998.] Journal of Gorgan University of Medical Sciences, 2001, 8:39-42 [in Farsi].

26. Centre for Disease Control sentinel site reports. Tehran, Islamic Republic of Iran, Ministry of Health and Medical Education, 2002.

27. Centre for Disease Control sentinel site reports. Tehran, Islamic Republic of Iran, Ministry of Health and Medical Education, 2003.

28. Rahimi Movaghar A, Mohammad K, Razaghi EM. [Trend of drug abuse situation in Iran: a three-decade survey.] Hakim research journal, 2002, 3:171-81 [in Farsi].
29. Rahimi Movaghar A et al. Assessment of shared injection equipment among IDUs: research report. Tehran, Islamic Republic of Iran, United Nations Office on Drugs and Crime, 2000.

30. Samiei M, Rafiei H, Taheri Nakhost HR. [Psychosocial profile of Iranian adolescent addicts.] Journal of rehabilitation, 2002, 10:56-62 [in Farsi].

31. Mokri A. Brief overview of the status of drug abuse in Iran. Archives of Iranian medicine, 2002, 5:184-90.

32. Rahimi Movaghar A. [Drug abuse prevalence and model in women.] Social welfare quarterly, 2004, 3:203-26 [in Farsi].

33. World report on knowledge for better health. Strengthening health systems. Geneva, World Health Organization, 2004.

34. Global ministerial forum on research for health. Strengthening research for health, development, and equity. Bamako, Mali, 17-19 November, 2008 (http://www.bamako2008.org, accessed 20 October 2009).

35. Majdzadeh R et al. Iran's approach to knowledge translation. Iranian journal of public health, 2009, 38(Suppl. 1):58-60.

\section{HIV prevention and care among injecting drug users in the Islamic Republic of Iran: a review of best practice}

This document reviews the implementation of harm reduction programmes, care and support services for people living with HIV/AIDS, and the attempts to reach and deliver services to hidden populations of injecting drug users in the Islamic Republic of Iran. It is intended for programme managers and policy-makers in all countries in order to share the Iranian experience as a model for a comprehensive approach to introducing and scaling up harm reduction. In addition to identifying harm reduction programme elements and their implementation, the document can also be a useful resource for advocacy.

A number of recommendations are also provided in order to enhance the Iranian response to HIV among injecting drug users. These recommendations can be used by policy-makers and programme managers in the Islamic Republic of Iran to improve and accelerate the positive impact of the services. They may also serve as useful programmatic tips for programme developers currently setting up harm reduction services in other countries of the Region.

The full text of this document is freely available at: http://www.emro.who.int/asd/pdf/hiv_review_iran.pdf 